\title{
Destruxin E Decreases Beta-Amyloid Generation by Reducing Colocalization of Beta-Amyloid-Cleaving Enzyme 1 and Beta-Amyloid Protein Precursor
}

\author{
Naohiro Itoh ${ }^{\mathrm{a}, \mathrm{b}}$ Masayasu Okochi ${ }^{\mathrm{a}}$ Shinji Tagami ${ }^{\mathrm{a}}$ Kouhei Nishitomi ${ }^{\mathrm{a}, \mathrm{b}}$ Taisuke Nakayama ${ }^{\mathrm{a}}$ \\ Kanta Yanagida $^{a}$ Akio Fukumori ${ }^{a}$ Jingwei Jiang ${ }^{a}$ Kohji Mori ${ }^{a}$ Motoko Hosono ${ }^{b}$ \\ Jyunko Kikuchic ${ }^{c}$ Yuko Nakano ${ }^{c}$ Yoshihiko Takinami ${ }^{d}$ Keiji Dohi ${ }^{\mathrm{e}}$ Atsuko Nishigaki $^{\mathrm{e}}$ \\ Hiroshi Takemoto $^{\text {e }}$ Kazuyuki Minagawa ${ }^{f}$ Takaaki Katoh $^{f}$ Michael Willem $^{\text {h }}$ Christian Haass $^{\text {h }}$ \\ Takashi Morihara $^{a}$ Toshihisa Tanaka ${ }^{a}$ Takashi Kudo ${ }^{a}$ Hiroshi Hasegawag Masaki Nishimurag

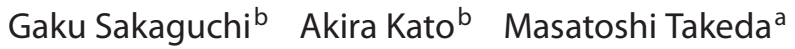

\begin{abstract}
a Psychiatry, Department of Integrated Medicine, Division of Internal Medicine, Osaka University Graduate School of Medicine, and ${ }^{b}$ Pain and Neurology, ${ }^{c}$ Analytical Chemistry, ${ }^{d}$ Discovery Technology $1,{ }^{e}$ Discovery Technology 2 and ${ }^{\mathrm{f} D i s c o v e r y}$ Chemistry, Shionogi \& Co. Ltd., Osaka, and ${ }^{9}$ Neurology Unit, Molecular Neuroscience Research Center, Shiga University of Medical Science, Otsu, Japan; 'h Laboratory for Alzheimer's and Parkinson's Disease Research, Department of Biochemistry, Adolf Butenandt Institute, Ludwig Maximilian University, Munich, Germany
\end{abstract}

\section{Key Words}

Alzheimer disease $\cdot$ Amyloid $\beta$ peptides .

$\beta$-Amyloid-cleaving enzyme $\cdot \beta$-Amyloid protein precursor •

Destruxin $E \cdot$ Notch signaling $\cdot$ Presenilin $/ \gamma$-secretase

\begin{abstract}
Alzheimer-disease-associated $\beta$-amyloid $(A \beta)$ is produced by sequential endoproteolysis of $\beta$-amyloid protein precursor ( $\beta A P P)$ : the extracellular portion is shed by cleavage in the juxtamembrane region by $\beta$-amyloid-cleaving enzyme $(\mathrm{BACE}) / \beta$-secretase, after which it is cleaved by presenilin (PS) $/ \gamma$-secretase near the middle of the transmembrane domain. Thus, inhibition of either of the secretases reduces $A \beta$ generation and is a fundamental strategy for the development of drugs to prevent Alzheimer disease. However, it is not clear how small compounds reduce $A \beta$ production without inhibition of the secretases. Such compounds are expected to avoid some of the side effects of secretase inhibi-
\end{abstract}

\section{KARGER}

Fax +41613061234 E-Mail karger@karger.ch www.karger.com
(C) 2009 S. Karger AG, Basel

$1660-2854 / 09 / 0066-0230 \$ 26.00 / 0$

Accessible online at:

www.karger.com/ndd tors. Here, we report that destruxin E (Dx-E), a natural cyclic hexadepsipeptide, reduces $A \beta$ generation without affecting $B A C E$ or $P S / \gamma$-secretase activity. In agreement with this, Dx-E did not inhibit Notch signaling. We found that Dx-E decreases colocalization of BACE 1 and $\beta A P P$, which reduces $\beta$-cleavage of $\beta A P P$. Therefore, the data demonstrate that Dx-E represents a novel $A \beta$-reducing process which could have fewer side effects than secretase inhibitors.

Copyright $\odot 2009$ S. Karger AG, Basel

Inhibition of $\beta$-amyloid $(A \beta)$ generation and enhancement of its degradation are proposed as major strategies for the treatment of Alzheimer disease [1,2]. A number of compounds have been developed to inhibit $\beta$-secretase [i.e. $\beta$-amyloid-cleaving enzyme (BACE)]

\section{N.I., M.O. and S.T. contributed equally to this work.}

Masayasu Okochi, MD

Psychiatry, Department of Integrated Medicine, Division of Internal Medicine Osaka University Graduate School of Medicine, D3, Yamada-oka 2-2, Suita Osaka 565-0871 (Japan)

Tel. +81 66879 3053, Fax +8166879 3059, E-Mail mokochi@psy.med.osaka-u.ac.jp 
and $\gamma$-secretase [i.e. a complex including presenilin (PS), nicastrin, Aph1 and Pen2] enzymes that are involved in the generation of $A \beta$. Because these compounds are expected to inhibit the physiological degradation of other secretase substrates, they may have side effects [3-5]. In fact, PS1 knockout mice die perinatally and show the Notch phenotype due to attenuation of NICD (Notch intracellular cytoplasmic domain) generation from Notch receptors $[6,7]$. BACE1 knockout mice also show the peripheral nerve hypomyelination phenotype caused by ablation of neuregulin 1 cleavage [5]. It is unclear whether targeting secretases is necessary for inhibiting $A \beta$ generation.

Here, we performed high-throughput screening for inhibitors of $A \beta$ generation and identified destruxin $\mathrm{E}$ (Dx-E), a natural compound derived from an entomopathogenic fungus. Interestingly, Dx-E reduced $\beta$-cleavage of $\beta$-amyloid protein precursor ( $\beta$ APP) but did not inhibit the secretases. The existence of such a compound suggests that there is a novel mechanism for inhibiting $\mathrm{A} \beta$ generation.

\section{Materials and Methods}

\section{Antibodies and Reagents}

Anti-A $\beta$ antibodies 6E10 and 4G8 were from Signet Laboratories (Dedham, Mass., USA). The anti-sAPP $\beta$ Swedish (sw) antibody was from IBL (Takasaki, Japan). The anti-BACE1 antibody was from Chemicon (Temecula, Calif., USA). The anti- $\mathrm{Na}^{+}-\mathrm{K}^{+}-$ ATPase was from Upstate Biotechnology. The anti-calnexin antibody was from Stressgen. The anti-early-endosome-antigen (EEA) and anti-GM130 antibodies were from BD Transduction Laboratories. The $\gamma$-secretase inhibitors DAPT and L-685,458 and the BACE inhibitor N-(1S,2R)-1-benzyl-3-(cyclopropylamino)-2-hydroxypropyl-5-[methyl(methylsulfonyl)amino- $\mathrm{N}^{\prime}$-(1R)1-phenylethyl]isophthalamide (inhibitor IV) were purchased from Calbiochem (San Diego, Calif., USA). The $\gamma$-secretase substrate NMA-GGVVIATVK(DNP)-DRDRDR-NH $\mathrm{N}_{2}$ was purchased from Calbiochem, and the $\beta$-secretase substrate MOCAcSEVNLDAEFRK(Dnp)-RR- $\mathrm{NH}_{2}$ was from Peptide Institute (Osaka, Japan). Dx-E was purified by Shionogi and Co. Ltd. In the measurement of $A \beta 40$ and $A \beta 42$ at a 384-well plate format, the addition of compounds and seeding of $\beta A P P$-overexpressing cells were simultaneously performed and incubated for $24 \mathrm{~h}$. In other experiments, compounds were mixed in culture medium and layered onto adherent cells.

\section{Cell Culture}

K293 and SH-SY5Y cells stably expressing $\beta$ APP/PS1/Notch derivatives were maintained in DMEM containing 10\% FCS and antibiotics $(200 \mu \mathrm{g} / \mathrm{ml}$ G418 for $\beta$ APP selection, $200 \mu \mathrm{g} / \mathrm{ml} \mathrm{zeo}$ cin for PS1 selection and $100 \mu \mathrm{g} / \mathrm{ml}$ hygromycin for Notch1 selection).
Measurement of $A \beta$ Secretion

For high-throughput screening, $\mathrm{A} \beta 40$ secretion was measured with a homogeneous time-resolved fluorescence kit (Nihon Schering, Osaka, Japan) as described in the manufacturer's instructions. Briefly, in a typical 384 -well plate assay, $55 \mathrm{ng} / \mathrm{ml}$ antibody europium cryptate, $400 \mathrm{ng} / \mathrm{ml}$ antibody XL665 and $50 \mathrm{mM}$ phosphate buffer (pH 7.4) containing $0.2 \%$ BSA and $0.5 \mathrm{M} \mathrm{FK}$ were added into each well. Samples of conditioned cell culture medium or synthetic peptide standards were added to give a total assay volume of $20 \mu \mathrm{l} /$ well. The reaction mixture was left at $4^{\circ} \mathrm{C}$ to allow equilibrium binding and then read on an ALVO multilabel counter (Wallac Oy and Perkin Elmer Inc., Turku, Finland). For measurement of $A \beta 40$ and $A \beta 42$ in a 96-well plate format, an $A \beta$ sandwich enzyme-linked immunosorbent assay (Wako, Japan) was used. The cells were incubated for $16 \mathrm{~h}$ with compounds. A $\beta$ levels were normalized by cell viability as measured using a WST system (Nacalai Tesque, Japan).

\section{Pulse-Chase Experiments}

Pulse-chase experiments were carried out as previously described [8].

Notch Downstream Assays

Notch signal reporter assays were carried out as previously described [9].

In vitro $\beta$-Secretase Assay

The peptide substrate for $\beta$-secretase (biotin-X-SEVNLDAEFRHDSGC) was labeled with europium cryptate (CIS Bio, Marcoule, France). Recombinant ectodomain human BACE1 (R \& D Systems) in reaction buffer (50 mM sodium acetate, $\mathrm{pH} 5.0$, and $0.008 \%$ Triton X-100) with various concentrations of inhibitors were mixed with the substrate $(18 \mathrm{nM})$ in 96 -well plates and then incubated for $3 \mathrm{~h}$ at $30^{\circ} \mathrm{C}$. Streptavidin-XL665 (0.4 $\mu \mathrm{g} /$ well) was added, and the reaction was incubated for $1 \mathrm{~h}$ at $30^{\circ} \mathrm{C}$. The homogeneous time-resolved fluorescence value [(ratio of fluorescence at $665 \mathrm{~nm}$ to that at $620 \mathrm{~nm}) \times 10,000]$ in each well was measured using an ALVO multilabel counter.

In vitro $\gamma$-Secretase Assay

Cell-free in vitro $\gamma$-secretase assays were carried out as previously described $[10,11]$.

\section{Cell-Free $\beta$-Secretase Assay}

Following starvation in methionine- and serum-free minimal essential medium for $40 \mathrm{~min}$, the K293 cells stably expressing sw $\beta A P P$ were metabolically labeled with $450 \mu \mathrm{Ci}$ of $\left[{ }^{35}\right.$ S $]$ methionine/cysteine (Redivue Promix; Amersham) for 20 min in methionine- and serum-free minimal essential medium. The crude membrane fraction was extracted, and the cell-free assay was performed as previously described with a minor change [12]. Briefly, samples of the crude membrane fraction were preincubated with each compound for $1 \mathrm{~h}$ and then incubated for 40 min at $37^{\circ} \mathrm{C}$ (cell-free incubation). The reaction was solubilized by the addition of $10 \times$ radioimmunoprecipitation assay buffer ( $1 \%$ sodium dodecyl sulfate, $5 \%$ deoxycholate, $10 \%$ Triton-X 100 ) and diluted with phosphate-buffered saline containing protease inhibitor cocktail. The $\beta$ APP C-terminal fragments (CTF) produced during the cell-free reaction were immunoprecipitated with antiserum 6618 [12]. Immunoprecipitates were separated on 
10-20\% Tris-tricine gels (Invitrogen, Carlsbad, Calif., USA) and analyzed by autoradiography.

\section{Immunocytochemistry}

K293 cells stably expressing sw $\beta$ APP and wild-type (wt) PS1 were cultured on poly-L-lysine-coated coverslips. Cells were treated with the reagents at indicated concentrations for $16 \mathrm{~h}$. Cells were fixed in $4 \%$ paraformaldehyde, permeabilized by $0.1 \%$ Triton-X 100 and blocked with $1 \%$ defatted milk, in phosphate-buffered saline. The following primary antibodies were used for immunostaining: Monoclonal antibodies for BACE1 and $\beta A P P$ (22C11) were from Chemicon. Polyclonal antibody for N-terminal (46-65) BACE1 was from Calbiochem. Polyclonal antibody 6618 was raised against the $C$ terminus of $\beta A P P$ [12]. Secondary antibodies used were labeled with Alexa 488 or 594 (Invitrogen).

\section{Subcellular Fractionation}

Subcellular fractionation was carried out as previously described [12].

\section{Results}

\section{$D x-E$ Inhibits $A \beta$ Generation}

A search for inhibitors of $A \beta$ generation in a library of more than approximately 50,000 compounds by highthroughput screening identified Dx-E, a cyclodepepsipeptide (fig. 1A). To confirm the ability of Dx-E to inhibit $A \beta$ generation, we labeled SH-SY5Y cells stably expressing wt $\beta$ APP by a $30-$ min pulse with $\left[{ }^{35} \mathrm{~S}\right]$ methionine followed by a 2 -hour chase. As shown in figure $1 B$, Dx-E $(1 \mu \mathrm{M})$ decreased the level of secreted $A \beta / \mathrm{p} 3$ species ( $\mathrm{IC}_{50}$ approx. $230 \mathrm{nM}$; fig. 1B, upper panel), although it did not significantly change the rate of $\beta A P P$ holoprotein degradation (fig. 1B, middle and lower panels). We also examined whether Dx-E affects the rate of $\mathrm{A} \beta$ degradation in cell culture. Cells were incubated in conditioned medium containing radiolabeled $A \beta$ and in the absence or presence of $\mathrm{Dx}-\mathrm{E}$. As shown in figure $1 \mathrm{C}$, the rate of $\mathrm{A} \beta$ degradation was unchanged by $\mathrm{Dx}$-E treatment. Thus, it appears that $\mathrm{Dx}-\mathrm{E}$ inhibits $\mathrm{A} \beta / \mathrm{p} 3$ generation in cell culture.

\section{$D x$-E Does Not Affect $\gamma$-Secretase Cleavage of $\beta A P P$}

$\mathrm{A} \beta$ generation requires two independent proteolytic steps, namely $\beta$ - and $\gamma$-cleavages. We first evaluated the possibility that $\mathrm{Dx}-\mathrm{E}$ reduces $\gamma$-secretase activity. We performed an in vitro $\gamma$-secretase assay [10] using an intramolecularly quenched fluorogenic peptide probe, NMA-GGVVIATVK(DNP)-DRDRDR-NH 2 . This probe was mixed with the 1\% CHAPSO-soluble membrane fraction of cultured cells (containing active PS/ $\gamma$-secretase complex) and incubated for $16 \mathrm{~h}$ with $\mathrm{Dx}-\mathrm{E}$ or
L685,458, a specific $\gamma$-secretase inhibitor. As shown in figure $2 \mathrm{~A}, \mathrm{Dx}-\mathrm{E}(0.003-10 \mu \mathrm{M})$ did not affect $\gamma$-secretase activity in vitro, although L-685,458 inhibited the activity in a dose-dependent manner. Next, we analyzed whether Dx-E inhibits $\gamma$-cleavage of $\beta A P P$ in living cells (fig. 2B). For the experiments, we used K293 cells stably expressing the CTF of $\beta$ APP (CTF100), a constitutive substrate for PS/ $\gamma$-secretase. In contrast to the case of full-length $\beta A P P, D x-E$ did not inhibit $A \beta$ generation from CTF100 (fig. 2B). Collectively, these results show that the reduction of $\mathrm{A} \beta$ generation by $\mathrm{Dx}-\mathrm{E}$ is not due to inhibition of $\gamma$-secretase/cleavage.

Modulators of $\gamma$-secretase, such as a subset of nonsteroidal anti-inflammatory drugs, can inhibit $A \beta$ generation at relatively higher concentrations than those causing changes in the relative ratio of $A \beta 42$ generation [13]. We therefore investigated whether Dx-E is a $\gamma$-secretase modulator. Pulse-chase experiments revealed that $\mathrm{Dx}-\mathrm{E}$ does not change the relative ratio of $\mathrm{A} \beta 42$ species at lower concentrations, indicating that it is not a $\gamma$-secretase modulator.

\section{Dx-E Does Not Affect Notch1 Degradation or Notch Signaling}

The major side effects of $\gamma$-secretase-inhibiting compounds are due to inhibition of Notch signaling. If $\mathrm{Dx}-\mathrm{E}$ does not affect the activity of PS/ $\gamma$-secretase, it should have no influence on Notch signaling. To confirm this, we examined whether Dx-E affects Notch signaling in cell culture (fig. 3A). We used cells stably expressing the N1CS construct, a derivative of the Notch1 receptor [14]. The N1CS polypeptide constitutively undergoes sequential endoproteolysis in the absence of ligand binding [14]. The extent of Notch signaling was determined using a luciferase reporter assay in cells expressing HES-Y [9]. As shown in figure $3 \mathrm{~A}, \mathrm{Dx}$-E treatment did not affect the rate of Notch signal transmission, although it dose-dependently reduced A $\beta$ production. Also, as expected, DAPT, a specific $\gamma$-secretase inhibitor, reduced both $A \beta$ generation and Notch signaling (fig. 3B). Therefore, Dx-E does not perturb Notch signaling even though it inhibits $A \beta /$ p3 generation.

The sequential endoproteolysis of Notch1 consists of S2/S3/S4 cleavages. NICD is generated by the S3 cleavage. Because Dx-E has distinct effects on the generation of $A \beta$ and NICD, we examined whether its effects are substrate specific. Thus, we analyzed secretion of S2/S4 cleavagederived $\mathrm{N} \beta$, also known as Notch1 A $\beta$-like peptides [8, 15] (fig. 3C). In contrast to specific $\gamma$-secretase inhibitors, Dx-E treatment did not inhibit N $\beta$ secretion from N1CS- 

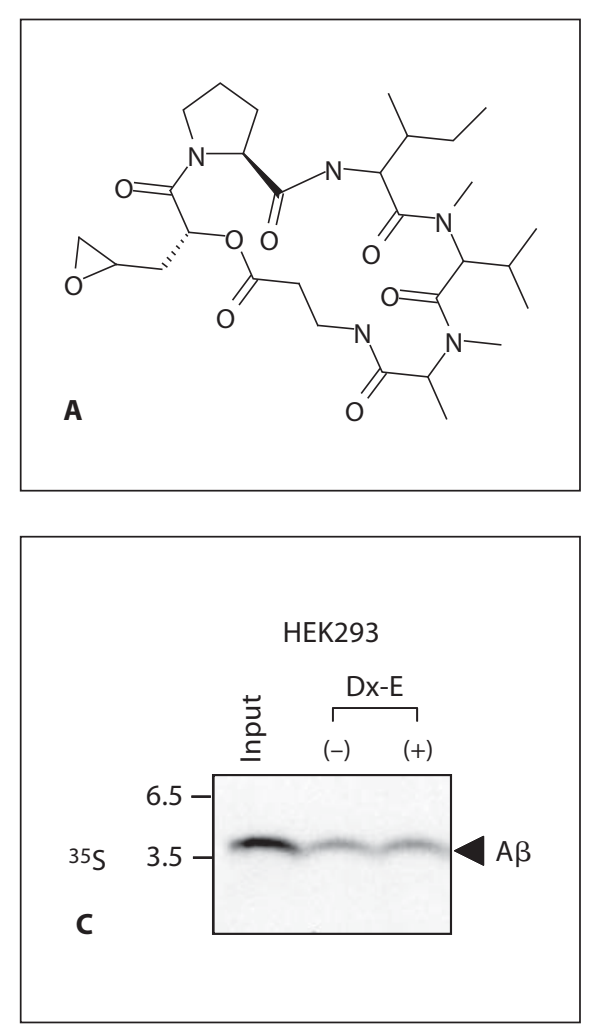

Fig. 1. Effects of $D x-E$ on $A \beta$ production and degradation. A Structure of Dx-E. B Effect of Dx-E on $\beta$ APP metabolism. Pulsechase analysis of $\beta$ APP metabolites was performed in SH-SY5Y cells stably expressing wt $\beta$ APP. Cells were labeled with a 30 -min pulse of $\left[{ }^{35} \mathrm{~S}\right]$ methionine followed by a 2 -hour chase. The conditioned media were collected and immunoprecipitated with antibody 4G8 (A $\beta$; upper panel). The $\beta$ APP holoprotein was immunoprecipitated from cell lysate using antiserum 6618 [12] (middle panel). Immunoprecipitates were separated by SDS-PAGE and analyzed by autoradiography, and the relative decrease in ${ }^{35} \mathrm{~S}$ in-

expressing cells (fig. 3C). Therefore, it appears that Dx-E inhibits sequential endoproteolysis of $\beta$ APP but not of Notch1.

\section{$D x$-E Does Not Affect $\beta$-Cleavage of $\beta A P P$ in vitro}

$D x-E$ reduces $A \beta$ generation without affecting $\gamma$ cleavage of $\beta A P P$ or Notch signaling/cleavage. Therefore, we examined whether Dx-E affects $\beta$-cleavage of $\beta A P P$ by BACE. We examined $\beta$-secretase activity in vitro using an intramolecularly quenched fluorogenic peptide probe, MOCAc-SEVNLDAEFRK(Dnp)-RR-NH $\mathrm{N}_{2}$, and recombinant BACE1. Dx-E did not affect BACE1 activity at any concentration of Dx-E tested $(0.6 \mathrm{nM}$ to $10 \mu \mathrm{M})$,
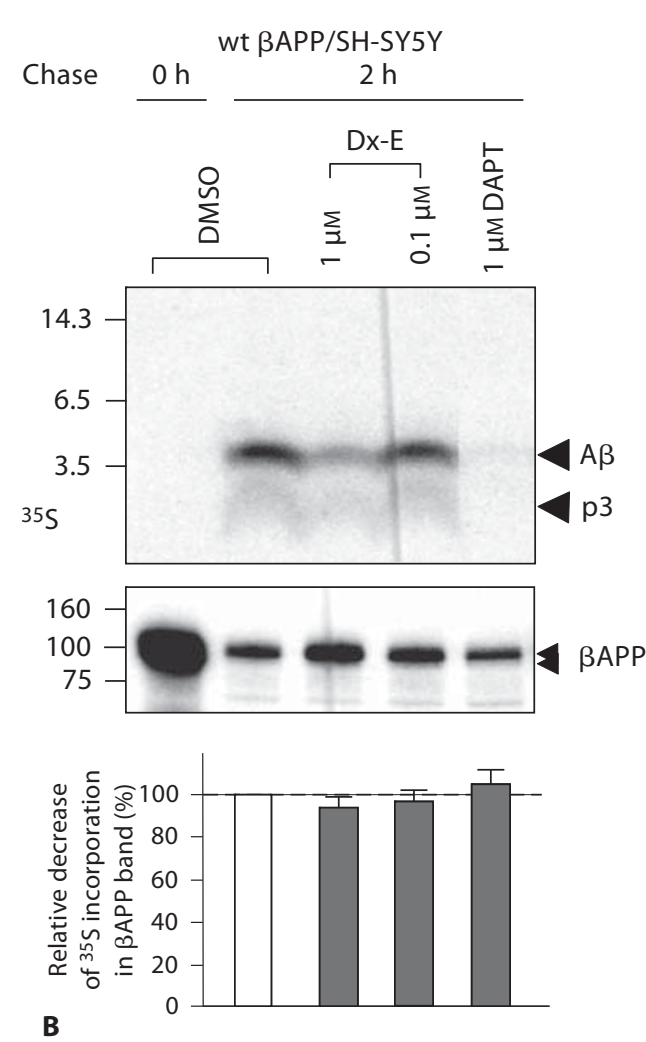

corporation in $\beta$ APP holoprotein was analyzed by fluorography using a STORM 820 (Amersham). The ratio of $\beta A P P$ holoprotein degradation during the 2-hour chase period in untreated cells was defined as $100 \%$. C Effect of Dx-E on degradation of A $\beta$ in cell culture. K293 cells stably expressing sw $\beta$ APP were metabolically labeled with a 30 -min pulse of $\left[{ }^{35} \mathrm{~S}\right]$ methionine followed by a $2-$ hour chase. The medium containing labeled $A \beta$ was transferred to unlabeled cells. The cells were then cultured in the presence or absence of Dx-E for $3 \mathrm{~h}$. The labeled conditioned media were collected and immunoprecipitated with 4G8. although the specific BACE inhibitor, inhibitor IV ( $\mathrm{IC}_{50}$ approx. $20 \mathrm{nM}$ ), affected the activity (fig. 4A). We also used a newly established cell-free $\beta$-secretase assay that can detect de novo generation of CTF $\beta$ from $\beta$ APP holoprotein (fig. $4 \mathrm{~B}$ ). After a 20 -min pulse with $\left[{ }^{35} \mathrm{~S}\right]$ methionine, we extracted the crude membrane fraction from cultured cells and incubated it for $40 \mathrm{~min}$ in vitro. Notably, addition of Dx-E to the membrane fraction did not decrease the generation of CTF $\beta$, although inhibitor IV decreased the level of CTF $\beta$ by approximately $70 \%(\mathrm{p}<$ 0.001 ( $\mathrm{t}$ test); fig. 4B, lower panel). These results indicate that $\mathrm{Dx}-\mathrm{E}$ does not affect BACE activity. 

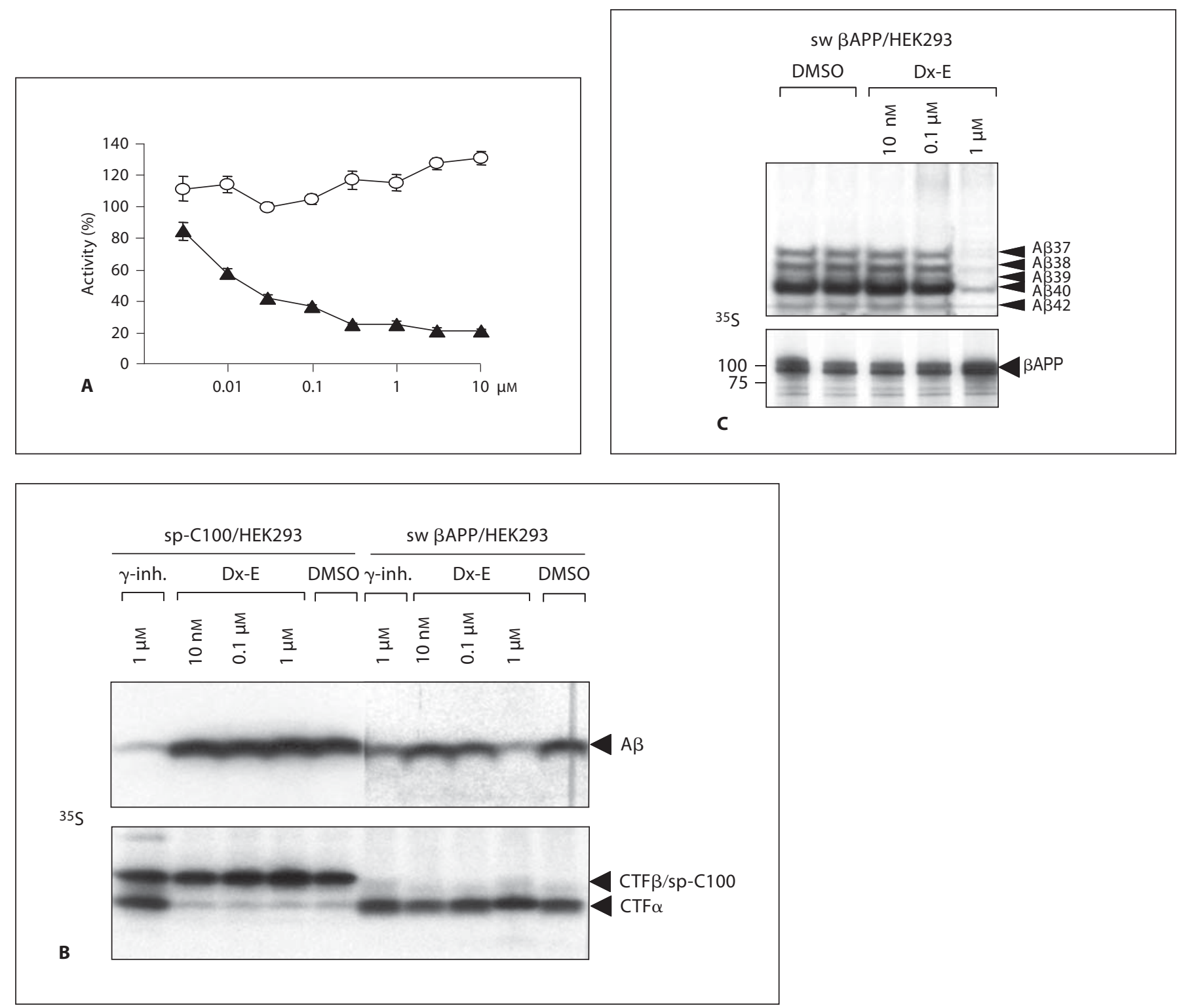

Fig. 2. Effects of Dx-E on $\gamma$-secretase/cleavage. A In vitro analysis of $\gamma$-secretase activity. $1 \%$ CHAPSO-solubilized crude membrane fraction was mixed with an intramolecularly quenched fluorogenic peptide probe and various concentrations of Dx-E (open circles) or L-685,458 (filled triangles). B Cell-based assay of $\gamma$ cleavage. K293 cells stably expressing sp-C100 (BAPP-C100 se- quence is connected to downstream of signal sequence of $\beta A P P$ ) were incubated with Dx-E for 16 h; inh. = inhibitor. C Cell-based assay of $\gamma$-modulation. K293 cells stably expressing sw $\beta$ APP were used. $A \beta$ in conditioned media was immunoprecipitated with antibody $4 \mathrm{G} 8$ and separated by Tris-bicine SDS-PAGE.

at the same concentration that reduced $A \beta$ generation (fig. $4 \mathrm{C}$, first panel, and fig. 4D, upper panel). In addition, Dx-E slightly enhanced the secretion of soluble $\beta A P P \alpha$, which is probably a secondary effect due to decreased $\beta$-cleavage of $\beta$ APP (fig. $4 \mathrm{D}$, lower panel). Dx-E affected neither the expression of BACE1 (fig. 4C, fourth panel) nor the maturation of $\beta \mathrm{APP}$ (fig. $4 \mathrm{C}$, second pan- 


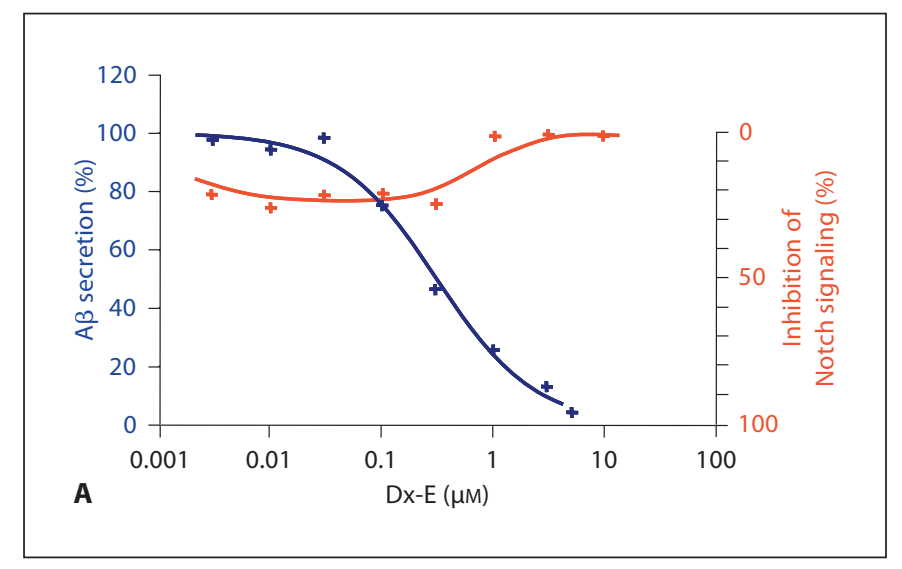

Fig. 3. Effects of Dx-E on Notch signaling/cleavage. A, B Notch downstream assay. After transient transfection with HES-Y and pRL-TK, cells stably expressing N1CS, sw $\beta$ APP and wt PS1 were treated with Dx-E (A) or DAPT (B) for 16 h. To analyze Notch signaling, the transcriptional activity of the HES-1 promoter was assessed in each condition (red). Conditioned media were collected, and the level of $A \beta$ was measured (blue). $C \mathrm{~N} \beta$ production assay. N1CS-expressing cells were labeled by pulse-chase with $\left[{ }^{35} \mathrm{~S}\right]$ methionine. Following treatment with $\gamma$-secretase inhibitors or Dx-E, the $\mathrm{N} \beta$ in conditioned media was analyzed by immunoprecipitation/autoradiography. Note that $\mathrm{N} \beta$ consists of two distinct molecular species (N 321 and $N \beta 25)$.

el). Therefore, Dx-E decreases $\beta$-cleavage of $\beta$ APP in living cells.

\section{$D x$-E Decreases Colocalization of $\beta A P P$ and BACE1 in Cultured Cells}

Our data that Dx-E decreases $\beta$-cleavage of $\beta A P P$ in living cells without targeting to BACE enzyme prompted us to study a possibility that it affects relative subcellular locations of BACE and $\beta A P P$. To address this, we performed immunohistochemical analysis (fig. 5A-J). In untreated cultured cells, immunostaining with anti- $\beta$ APP extracellular domain antibody $(22 \mathrm{C} 11$, red) and BACE1 N-terminal domain antibody (Calbiochem 195101, green) yielded substantial amounts of yellow colors which implies colocalization of the enzyme and the substrate (fig. 5A, B). However, upon Dx-E treatment, a portion of the yellow staining drastically decreased, while red/green stainings reciprocally increased (fig. 5C, D), indicating a marked decrease in the colocalization. In addition, we compared the distribution of each green or red staining with or without Dx-E treatment (fig. 5E-G, H-
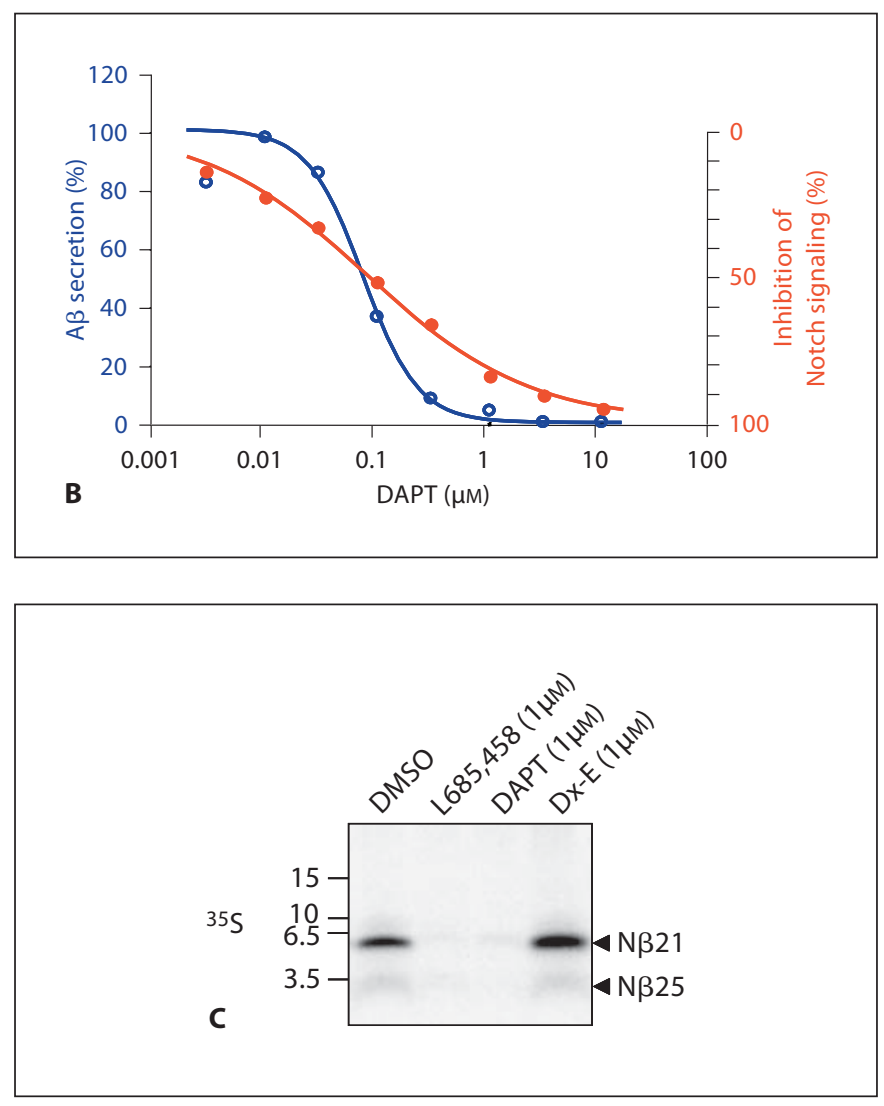

$J)$, and found that the change of BACE1 distribution looked greater than that of $\beta A P P$.

To further confirm that Dx-E decreases the colocalization of $\beta A P P$ and BACE1, we performed subcellular fractionation of cultured cells and observed the colocalization in each organelle. We immunoblotted each fraction with antibodies to the $\mathrm{Na}^{+}-\mathrm{K}^{+}$-ATPase $\alpha_{1}$-subunit (for plasma membrane marker), EEAl (for endosome marker), calnexin (for endoplasmic reticulum marker) and GM130 (for Golgi marker), which confirmed successful separation of each organelle (fig. 6A, B). Continuously, we tried to observe changes in subcellular distribution of $\beta A P P / B A C E 1$ with or without the treatment of Dx-E (fig. 6C). Strikingly, the major distribution of BACE1 moved from the relatively light fractions (approx. fractions 4-7) to heavier fractions (approx. fractions 7-9; fig. $6 \mathrm{C}$, first and second panels). However, distribution of $\beta A P P$ holoprotein and those of the organelle marker proteins did not change so much (fig. 6C, third to fourth panels, and fig. 6A, B). Both the biochemical and immunohistochemical data indicate that $\mathrm{Dx}-\mathrm{E}$ induces drastic 

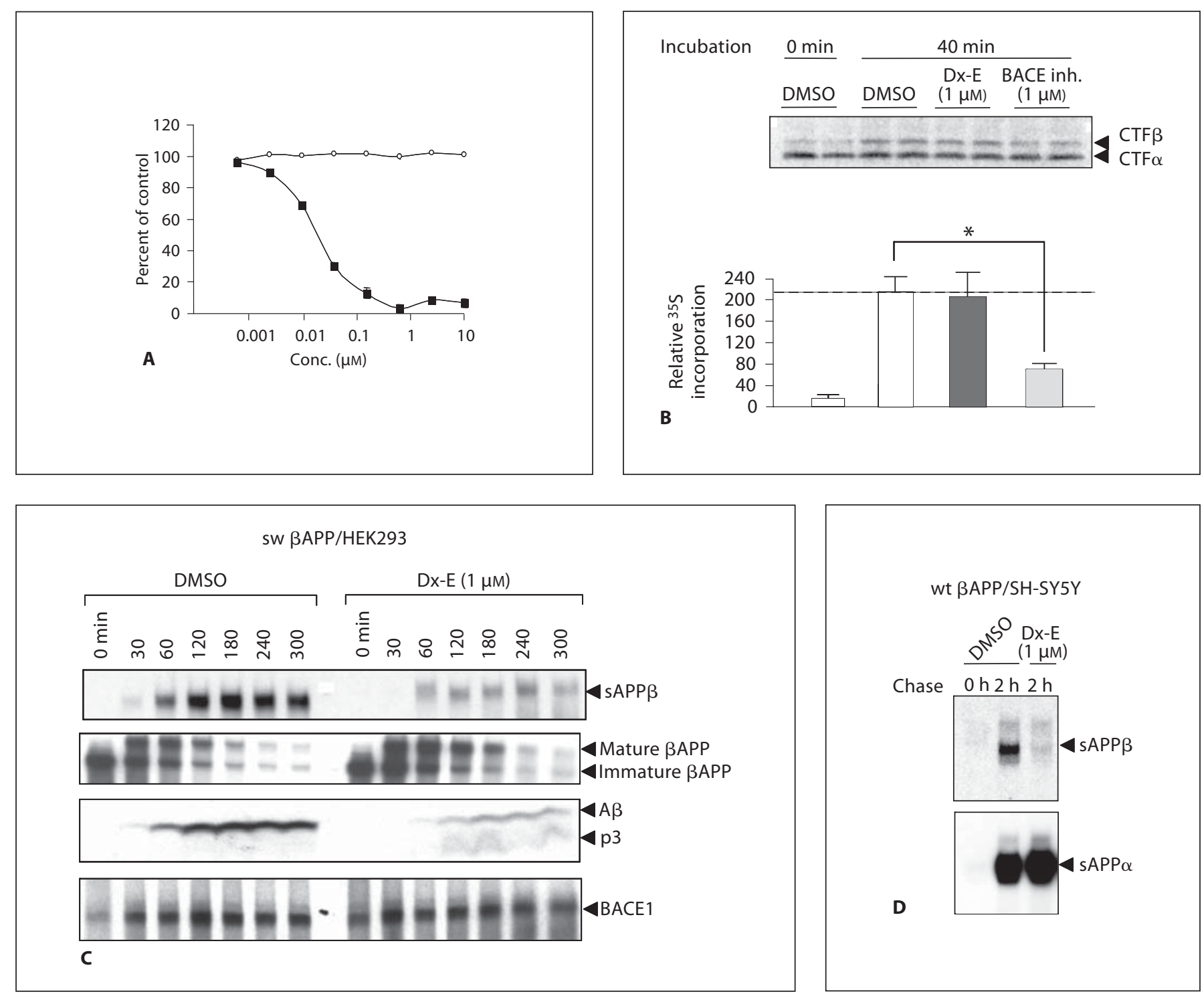

Fig. 4. Effects of Dx-E on $\beta$-secretase activity and $\beta$-cleavage of $\beta A P P$ in cell culture. A Recombinant BACE1 was mixed with substrates and various concentrations of Dx-E (open circles) or inhibitor IV (filled squares). B The crude membrane fraction from ${ }^{35}$ S]methionine-labeled K293 cells stably expressing sw $\beta A P P$ was prepared. The cell-free $\beta$-secretase activity was assessed by measuring the de novo production of CTF $\beta$; inh. = inhibitor; ${ }^{*} \mathrm{p}<0.001$. C Immunoprecipitation/autoradiography analysis of

changes in the subcellular locations of BACE1. Collectively, we suggest that $D x-E$ induces decreased colocalization of matured $\beta A P P$ holoprotein and BACE1 enzyme, which may reduce $\beta$-cleavage. $\beta A P P$ metabolites from K293 cells stably expressing sw $\beta$ APP and wt PS1. After $10 \mathrm{~min}$ of metabolic labeling with $\left[{ }^{35} \mathrm{~S}\right]$ methionine, the cells were chased at the indicated time points. The conditioned media were collected and immunoprecipitated with 4G8 $(\mathrm{A} \beta)$ or anti-sw-sAPP $\beta$ antibody. The levels of $\beta$ APP holoprotein and BACE1 in the cell lysates were also analyzed. D Production of sAPP $\beta$ and SAPP $\alpha$ by SH-SY5Y cells stably expressing wt $\beta A P P$.

\section{Discussion}

In this study, we demonstrated that $D x-E$ reduces $A \beta$ generation in a secretase-independent manner. Dx-E inhibits $\beta$-cleavage of $\beta$ APP, but it does not affect $\beta$ - and $\gamma$-secretases. Curiously, colocalization of BACE1 and 
Fig. 5. Effects of Dx-E on the subcellular location of BACE1 and $\beta A P P$. Cells were treated with dimethylsulfoxide (DMSO, A, B) or $1 \mu \mathrm{M} \mathrm{Dx}-\mathrm{E}(\mathbf{C}, \mathbf{D})$ for $16 \mathrm{~h}$. Then, $\beta A P P(\mathbf{E}, \mathbf{H})$ and $\operatorname{BACE} 1(\mathbf{F}, \mathbf{I})$ were immunostained, and cell nuclei were counter-stained with diamidinophenylindole (G, J).
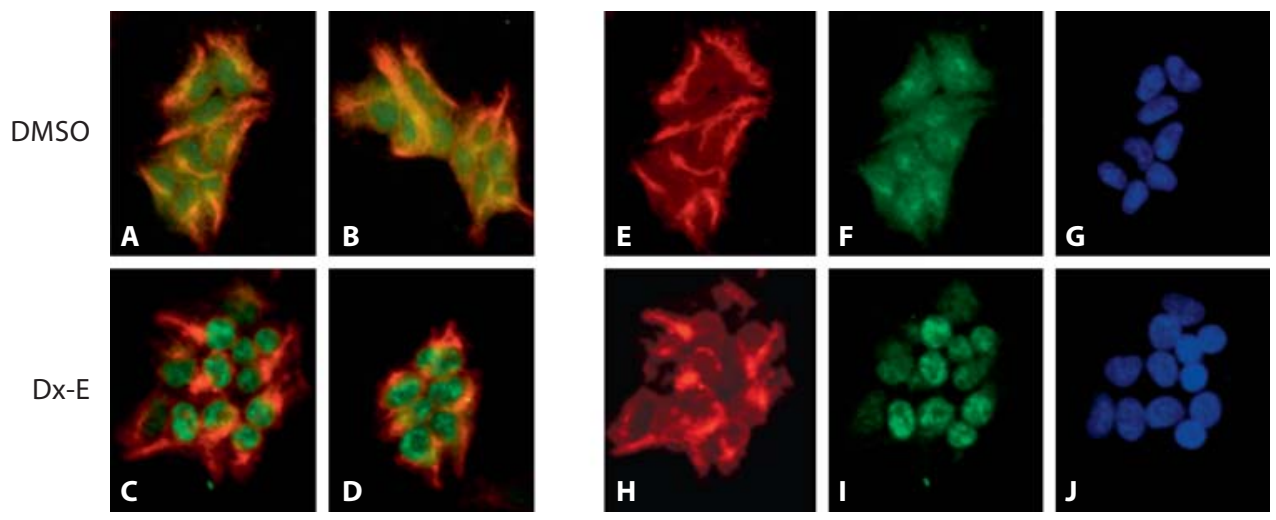
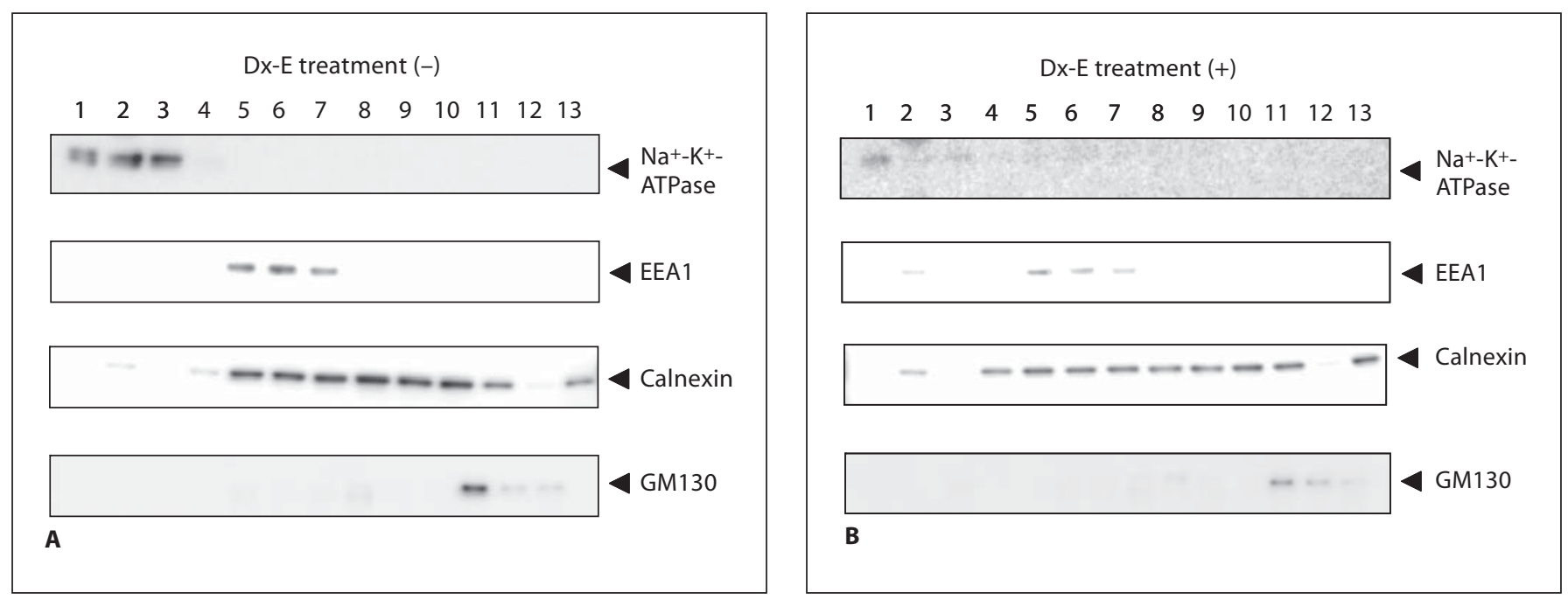

Fig. 6. Effects of Dx-E on subcellular location of BACE1 and $\beta A P P$. Fractions from a $8.0-25 \%$ linear iodixanol gradient examined by immunoblotting with the indicated antibodies. Cells were treated with dimethylsulfoxide (A and C, first and third panels) or $1 \mu \mathrm{M} \mathrm{Dx}-\mathrm{E}$ (B and C, second and fourth panels) for $16 \mathrm{~h}$ and homogenated followed by subcellular fractionation.

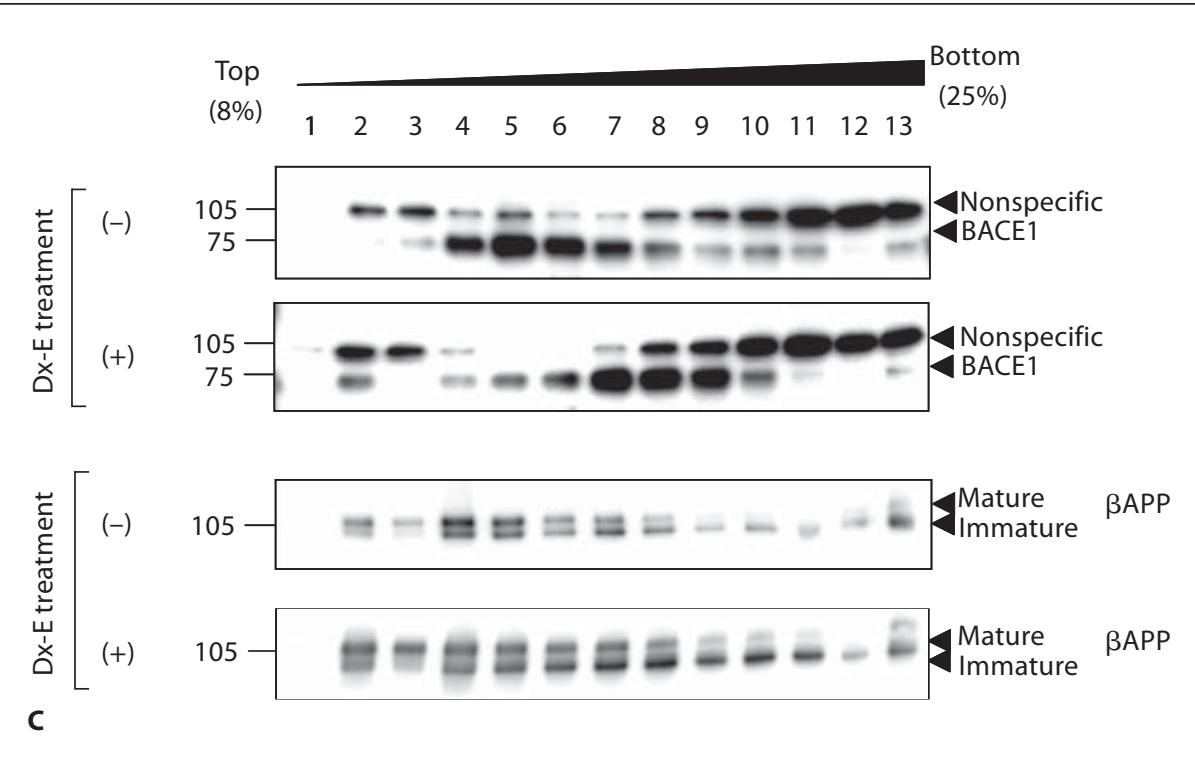


$\beta A P P$ was reduced by Dx-E. Our results suggest that DxE represents a novel and advantageous means of reducing $\mathrm{A} \beta$ production in Alzheimer disease.

Dx-E, a member of the destruxin family, is a cyclic hexadepsipeptide containing an $\alpha$-hydroxy acid and 5 amino acid residues [16]. This peptide is reported to have several biological activities, including inhibition of vacuolar-type $\mathrm{H}^{+}$-ATPase, cell cycle arrest and inhibition of bone resorption [16]. The ability of Dx-E to reduce $A \beta$ production might be related to these effects. In addition, $\mathrm{Dx}-\mathrm{E}$ is not the only member of the destruxin family that can inhibit $A \beta$ production; we found that destruxin $C$ is a weak inhibitor of $A \beta$ production [Itoh N., unpubl. observations]. Like Dx-E, bafilomycin and concanamycin inhibit the vacuolar-type $\mathrm{H}^{+}$-ATPase and reduce $A \beta$ secretion from sw- $\beta$ APP-expressing cells $[17,18]$. However, their mechanism of inhibiting $\beta$-cleavage is not well understood.

To reduce $A \beta$ generation, inhibitors of either $\beta$-cleavage or $\gamma$-cleavage of $\beta A P P$ have been developed. Since typical BACE or PS/ $\gamma$-secretase inhibitors inhibit the enzymatic activities, they inevitably perturb cleavages of substrates other than $\beta A P P$. Inhibiting the enzymatic activities may cause unfavorable side effects because these enzymes are deeply involved in neuregulin/Notch signaling and play important roles in vivo. Thus, atypical compounds have been of note which inhibit $A \beta$ generation without disturbing cleavages of other substrates. Especially, inhibitors that do not affect Notch signaling have been sought. For example, Gleevec ${ }^{\circledR}$ is thought to target the PS/ $\gamma$-secretase because it inhibits the de novo generation of $A \beta$ in a cell-free assay [19]. How other compounds such as JLK (nonpeptidic inhibitors of $\gamma$-secretase), glycogen synthase kinase $3 \alpha$ inhibitors, cerebrolysin and berberine inhibit $A \beta$ generation is unclear [2022].

Dx-E, which is neither a BACE nor PS/ $\gamma$-secretase inhibitor, can reduce $A \beta$ generation. Dx-E may decrease $A \beta$ by reducing colocalization of $\beta A P P$ and BACE1. The reduction of the colocalization is probably induced by drastic changes in the subcellular locations of BACE1. Since Dx-E does not change subcellular locations of other proteins such as $\beta A P P, \mathrm{Na}^{+}-\mathrm{K}^{+}$-ATPase $\alpha_{1}$-subunit, EEA1, calnexin and GM130, the effect of Dx-E may be specific to BACE1. Dx-E may specifically affect trafficking of BACE1. Further study will be needed to elucidate how it is achieved. In future, we expect research and development of small-molecule inhibitors with processes similar to Dx-E.

\section{Acknowledgements}

We are grateful to the Program for the Promotion of Fundamental Studies in Health Sciences of the National Institute of Biomedical Innovation (05-26) (to M.O., S.T. and M.T.) and KAKENHI from the Ministry of Education, Culture, Sports and Science of Japan (to M.O. and S.T.).

\section{References}

1 Selkoe DJ: Alzheimer's disease: genes, proteins, and therapy. Physiol Rev 2001;81:741766.

2 Saido TC, Iwata N: Metabolism of amyloid beta peptide and pathogenesis of Alzheimer's disease: towards presymptomatic diagnosis, prevention and therapy. Neurosci Res 2006;54:235-253.

3 Geling A, Steiner H, Willem M, Bally-Cuif L, Haass C: A gamma-secretase inhibitor blocks Notch signaling in vivo and causes a severe neurogenic phenotype in zebrafish. EMBO Rep 2002;3:688-694.

4 Searfoss GH, Jordan WH, Calligaro DO, Galbreath EJ, Schirtzinger LM, Berridge BR, Gao H, Higgins MA, May PC, Ryan TP: Adipsin: a biomarker of gastrointestinal toxicity mediated by a functional gamma secretase inhibitor. J Biol Chem 2003;278:4610746116.
5 Willem M, Garratt AN, Novak B, Citron M, Kaufmann S, Rittger A, De Strooper B, Saftig P, Birchmeier C, Haass C: Control of peripheral nerve myelination by the beta-secretase BACE1. Science 2006;314:664-666.

6 Shen J, Bronson RT, Chen DF, Xia W, Selkoe DJ, Tonegawa S: Skeletal and CNS defects in presenilin-1-deficient mice. Cell 1997;89: 629-639.

7 Wong PC, Zheng H, Chen H, Becher MW, Sirinathsinghji DJ, Trumbauer ME, Chen HY, Price DL, Van der Ploeg LH, Sisodia SS Presenilin 1 is required for Notch1 and DII1 expression in the paraxial mesoderm. Nature 1997;387:288-292.

8 Okochi M, Fukumori A, Jiang J, Itoh $\mathrm{N}$, Kimura R, Steiner H, Haass C, Tagami S, Takeda M: Secretion of the Notch-1 Abetalike peptide during Notch signaling. J Biol Chem 2006;281:7890-7898.
9 Tagami S, Okochi M, Yanagida K, Ikuta A, Fukumori A, Matsumoto N, Ishizuka-Katsura Y, Nakayama T, Itoh N, Jiang J, Nishitomi K, Kamino K, Morihara T, Hashimoto R, Tanaka T, Kudo T, Chiba S, Takeda M: Regulation of notch signaling by dynamic changes in the precision of $s 3$ cleavage of notch-1. Mol Cell Biol 2008;28:165-176.

10 Taniguchi Y, Karlstrom H, Lundkvist J, Mizutani T, Otaka A, Vestling M, Bernstein A, Donoviel D, Lendahl U, Honjo T: Notch receptor cleavage depends on but is not directly executed by presenilins. Proc Natl Acad Sci USA 2002;99:4014-4019.

11 Farmery MR, Tjernberg LO, Pursglove SE, Bergman A, Winblad B, Naslund J: Partial purification and characterization of gamma-secretase from post-mortem human brain. J Biol Chem 2003;278:24277-24284. 
12 Fukumori A, Okochi M, Tagami S, Jiang J, Itoh N, Nakayama T, Yanagida K, IshizukaKatsura Y, Morihara T, Kamino K, Tanaka T, Kudo T, Tanii H, Ikuta A, Haass C, Takeda M: Presenilin-dependent gamma-secretase on plasma membrane and endosomes is functionally distinct. Biochemistry 2006;45:49074914.

13 Takahashi Y, Hayashi I, Tominari Y, Rikimaru K, Morohashi Y, Kan T, Natsugari H, Fukuyama T, Tomita T, Iwatsubo T: Sulindac sulfide is a noncompetitive gamma-secretase inhibitor that preferentially reduces Abeta 42 generation. J Biol Chem 2003;278:1866418670.

14 Mumm JS, Schroeter EH, Saxena MT, Griesemer A, Tian X, Pan DJ, Ray WJ, Kopan R: A ligand-induced extracellular cleavage regulates gamma-secretase-like proteolytic activation of Notch1. Mol Cell 2000;5:197206.
15 Okochi M, Steiner H, Fukumori A, Tanii H, Tomita T, Tanaka T, Iwatsubo T, Kudo T, Takeda M, Haass C: Presenilins mediate a dual intramembranous gamma-secretase cleavage of Notch-1. Embo J 2002;21:54085416.

16 Pedras MS, Irina Zaharia L, Ward DE: The destruxins: synthesis, biosynthesis, biotransformation, and biological activity. Phytochemistry 2002;59:579-596.

17 Haass C, Capell A, Citron M, Teplow DB, Selkoe DJ: The vacuolar $\mathrm{H}^{+}$-ATPase inhibitor bafilomycin A1 differentially affects proteolytic processing of mutant and wild-type beta-amyloid precursor protein. J Biol Chem 1995;270:6186-6192.

18 Knops J, Suomensaari S, Lee M, McConlogue L, Seubert P, Sinha S: Cell-type and amyloid precursor protein-type specific inhibition of A beta release by bafilomycin A1, a selective inhibitor of vacuolar ATPases. J Biol Chem 1995;270:2419-2422.
19 Netzer WJ, Dou F, Cai D, Veach D, Jean S, Li Y, Bornmann WG, Clarkson B, Xu H, Greengard P: Gleevec inhibits beta-amyloid production but not Notch cleavage. Proc Natl Acad Sci USA 2003;100:12444-12449.

20 Phiel CJ, Wilson CA, Lee VM, Klein PS: GSK-3alpha regulates production of Alzheimer's disease amyloid-beta peptides. Nature 2003;423:435-439.

21 Petit A, et al: New protease inhibition. Nat Cell Biol 2001;5:507-511.

22 Asai M, Iwata N, Yoshikawa A, Aizaki Y, Ishiura S, Saido TC, Maruyama K: Berberine alters the processing of Alzheimer's amyloid precursor protein to decrease Abeta secretion. Biochem Biophys Res Commun 2007; 352:498-502. 